\title{
Incidence and 12-month outcome of non-transient childhood conversion disorder in the UK and Ireland
}

\author{
Cornelius Ani, Richard Reading, Richard Lynn, Simone Forlee and Elena Garralda
}

\section{Background}

Little is known about conversion disorder in childhood.

\section{Aims}

To document clinical incidence, features, management and 12-month outcome of non-transient conversion disorder in under 16-year-olds in the UK and Ireland.

\section{Method}

Surveillance through the British Paediatric Surveillance Unit and Child and Adolescent Psychiatry Surveillance System.

\section{Results}

In total, 204 cases (age range 7-15 years) were reported, giving a 12-month incidence of 1.30/100000 (95\% Cl 1.11-

1.52). The most common symptoms were motor weakness and abnormal movements. Presentation with multiple symptoms was the norm. Antecedent stressors were reported for $80.8 \%$, most commonly bullying in school. Most children required in-patient admission with frequent medical investigations. Follow-up at 12 months was available for 147 children, when all conversion disorder symptoms were reported as improved. Most families (91\%) accepted a nonmedical explanation of the symptoms either fully or partially.

\section{Conclusions}

Childhood conversion disorder represents an infrequent but significant clinical burden in the UK and Ireland.

\section{Declaration of interest}

None.
Conversion disorder refers to the presence of motor and or sensory symptoms for which there are no or inadequate medical explanations. ${ }^{1}$ Typical symptoms include motor weakness, abnormal movements, non-epileptic seizures, and loss of sight, hearing and touch. The symptoms are not deliberately produced and can be associated with significant distress. Affected children can present with varying degrees of severity. The prognosis of childhood conversion disorder is poorly documented but some children are known to become very impaired, requiring prolonged hospital admission and experiencing long-term physical and psychosocial complications including psychiatric comorbidity, social isolation and educational failure. ${ }^{2-4}$ Although cases of childhood conversion disorder have been documented in many countries, for the most part this is based on small samples of children seen in specialist units, and epidemiological data are sparse. The most robust data from a national surveillance study of Australian children under 16 years identified 194 newly diagnosed cases in the care of paediatric clinicians over 2 years, giving a yearly incidence of 2.3-4.2 per $100000 .^{2}$ Most were female (71\%), motor symptoms were most common but half presented with multiple symptoms. Experience of separation and family conflict were the most common antecedent stressors. The majority required hospital admission and utilised extensive medical and allied resources. Accurate data on the epidemiology, clinical features, service use and prognosis of conversion disorder are important in planning services and allocating resources for affected children. In this paper we present the first national study on the clinical incidence of non-transient childhood conversion disorder in the UK and Ireland, and report 1-year outcome.

\section{Method}

We adopted similar methodology to that used in the Australian clinical surveillance incidence study of conversion disorder. ${ }^{2}$ Active prospective surveillance was carried out by monthly mailing of all consultant paediatricians in the UK and Ireland through the British Paediatric Surveillance Unit (BPSU, see www.rcpch.ac.uk/bpsu) ${ }^{5}$ from 1 October 2008 to 31 December 2009 (15 months). Given that individuals with this condition may also present to child and adolescent psychiatrists, we used a similar system, the Child and Adolescent Psychiatric Surveillance System (CAPSS, see www.rcpsych.ac.uk/quality/research/capss1. aspx), to cover consultant child and adolescent psychiatrists. ${ }^{6}$ Jointly, the two surveillance systems represent all the consultant paediatricians and child and adolescent psychiatrists officially registered and practising in the UK and Ireland.

Clinicians were asked every month to report any cases of children seen with a new diagnosis of conversion disorder. A notification questionnaire (online supplement DS1) was sent to reporting consultants to ascertain whether the case definition was met and to obtain details of clinical data. Duplicate reports were excluded by matching on partial identification data. A panel of two consultant child and adolescent psychiatrists and a consultant paediatrician reviewed all notification questionnaires to decide by consensus whether the case definition was met. A follow-up outcome questionnaire (online supplement DS2) was sent after 1 year to all clinicians reporting confirmed cases.

The study was approved by the BPSU and CAPSS Executive Committees and by the Charing Cross Research Ethics Committee (Ref: 08/H0711/30). Section 60 exemption approval was given by the Patient Information Advisory Group (Ref: PIAG/BPSU 3-06(FT1)/2008) to allow notification of semi-anonymised data without patient and carer consent.

\section{Case definition}

The case definition was based on the DSM-IV criteria for conversion disorder, ${ }^{1}$ with an additional criterion of 7 days or longer duration to prevent reports of mild, transient cases. These were excluded as we were interested in children with problems clinically significant and burdensome enough to require 
assessment by consultant paediatricians and child and adolescent psychiatrists. Clinicians were asked to report any child under 16 years newly diagnosed with conversion disorder during the previous month if they had:

(a) one or more symptoms and/or signs affecting motor function (such as weakness, abnormal gait or movements, difficulty with swallowing, or loss of speech) and/or sensory function (such as loss or diminished sensation of touch, sight or hearing) and/or non-epileptic seizures (also known as pseudoseizures); and

(b) the symptoms and/or signs:

(i) could not be adequately explained by a medical condition after full investigation (according to the judgement of the treating clinician), and

(ii) there was no evidence that they have been intentionally produced, and

(iii) they caused significant distress and/or interference in daily activities such as with self-care, school attendance, play or family activities for up to 7 days or longer, and

(iv) were accompanied by psychological factors that were judged to be associated with or have contributed to the presentation.

Cases were excluded if the clinical picture was better explained by another psychiatric disorder such as somatoform disorder, depression, psychosis or tics.

\section{Statistical analysis}

Incidence of conversion disorder was calculated by dividing the number of confirmed cases with the base population of children younger than 16 years in the UK and Ireland over the 15-month surveillance period (standardised to 12 months) expressed as per 100000 population. For the UK, the mid-year population of children younger than 16 years in 2009 was obtained from the National Office for Statistics (www.ons.gov.uk/ons/publications/ re-reference-tables.html? edition $=\mathrm{tcm} \% 3 \mathrm{~A} 77-213645)$. For Ireland, similar data for 2009 were obtained from the Central Statistics Office (www.cso.ie/en/media/csoie/releasespublications/documents/ population/current/popmig.pdf).
Descriptive statistics were used for other data. Duplicate reports by different clinicians were treated summatively such that items were scored positive if so marked in either of the duplicate questionnaires. Cases have been subdivided into those in individuals under 10 years and those $10-15$ years of age to enable comparison with the Australian data. ${ }^{2}$ As there were missing data on clinician reporting of individual clinical features, all proportions have been calculated with the denominator as number of cases with complete data for that variable.

\section{Results}

A total of 2874 consultant paediatricians are registered with the BPSU: the response rate to card surveillance was 93\%. The number of consultant child and adolescent psychiatrists in the CAPSS database over the course of the study was 728 and the overall response rate to card surveillance $66.2 \%$. Figure 1 shows the flow of reported cases on the surveillance cards. There were 466 suspected cases, 251 reported by paediatricians and 215 by psychiatrists. Scrutiny by the notification review panel of questionnaires - which were returned for 337/466 (72\%) resulted in 204 children deemed to meet the inclusion criteria after removal of duplicates. A total of 147 (72\%) 1-year follow-up questionnaires were received.

\section{Incidence}

With a total estimated population of 12542420 children under 16 years in the UK and Ireland in 2009, the 204 confirmed cases over 15 months' surveillance provide a total 12 -month incidence of 1.30/100 000 (95\% CI 1.11-1.52). The incidence increased with age, being $0.26 / 100000$ (95\% CI 0.16-0.40) among children younger than 10 years and $3.04 / 100000(\mathrm{CI}=2.56-3.58)$ for children $10-15$ years old.

\section{Demographics}

The age range of the 204 confirmed cases was 7-15 years, the median 12.5 years (IQR 11-14). Three-quarters were females $(153 / 204,75 \%)$ : the gender distribution was comparable in younger children under 10 years (i.e. $19 / 25,76 \%$ female) and in

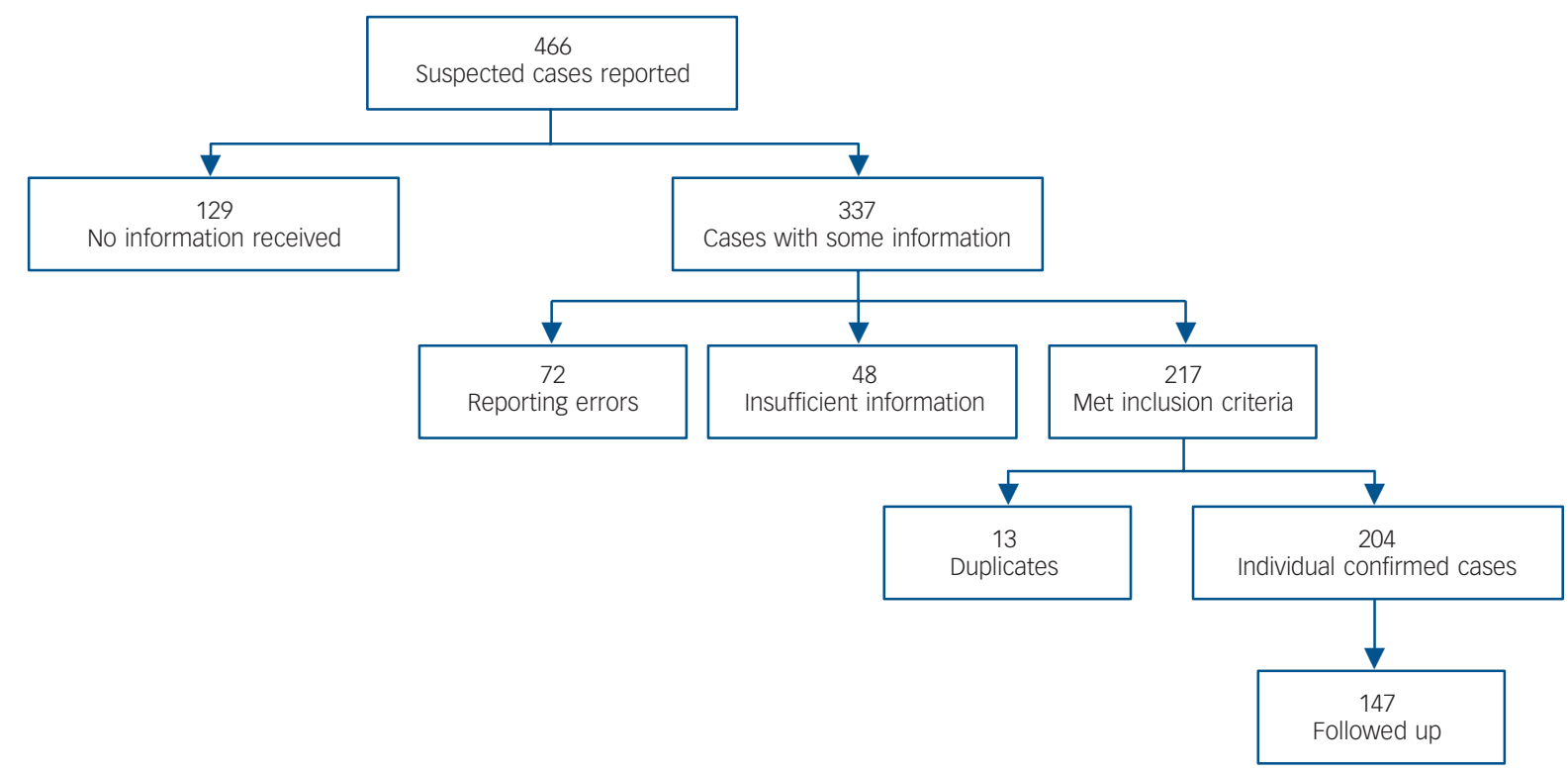

Fig. 1 Case flow 
the older group (i.e. 134/179, 75\% female). In total, $81.2 \%$ (164/ 202) were White British or Irish, whereas $18.8 \%$ (38/202) were described as 'non-White'.

\section{Clinical features}

For 166/203 individuals (82\%) this was their first episode of conversion disorder. The time from appearance of first typical symptom to diagnosis ranged from less than 1 week in $15 / 200$ children $(7.5 \%)$ to over 6 months for 26 children (13\%). Table 1 shows the main symptoms at first presentation. Motor weakness was the most common conversion symptom followed by abnormal movements and non-epileptic seizures. The majority (141/204; 69.1\%) presented with more than one core symptom;

\begin{tabular}{|c|c|c|}
\hline Symptoms & $n / N(\%)^{a}$ & Median (IQR) \\
\hline \multicolumn{3}{|l|}{ Core conversion symptoms } \\
\hline Motor weakness & $114 / 180(63.3)$ & \\
\hline Abnormal movement & $73 / 169(43.2)$ & \\
\hline Non-epileptic seizures & $66 / 165(40.0)$ & \\
\hline Anaesthesia/paraesthesia & $56 / 173(32.4)$ & \\
\hline Diminished consciousness & $47 / 162(29.0)$ & \\
\hline Visual loss & $37 / 161(23.0)$ & \\
\hline Limb paralysis & $34 / 157(21.7)$ & \\
\hline Loss of speech & 30/155 (19.4) & \\
\hline Hearing loss & $12 / 155(7.7)$ & \\
\hline \multicolumn{2}{|l|}{ Total number of core symptoms (range 1-9) } & $2(1-3)$ \\
\hline \multicolumn{3}{|l|}{ Associated non-core symptoms } \\
\hline Pain & $96 / 175(54.9)$ & \\
\hline Fatigue & $55 / 162(34.0)$ & \\
\hline La belle indifference & $45 / 166(27.1)$ & \\
\hline \multicolumn{2}{|l|}{$\begin{array}{l}\text { Total number of symptoms (both core } \\
\text { and non-core) (range 1-13) }\end{array}$} & $3(2-4.8)$ \\
\hline \multicolumn{3}{|c|}{$\begin{array}{l}\text { a. The denominators refer to the number of clinicians answering 'Yes' or 'No' to the } \\
\text { question on whether a child had a particular symptom. Blank or 'not known' answers } \\
\text { were treated as missing data. }\end{array}$} \\
\hline
\end{tabular}

$33 / 204(16.2 \%)$ had four or more symptoms. Pain and fatigue were also commonly reported alongside the core symptoms, and La belle indifference was reported to be present in a quarter of individuals. In 46 children where laterality of symptoms was reported, 22 were right-sided and 24 left-sided.

There were no significant differences in frequency of conversion disorder symptoms between the two age groups (under 10 years and $10-15$ years). Females were more likely to present with loss of consciousness compared with males (41/122 (34\%) v. $6 / 37(16 \%))\left(\chi^{2}=4.1\right.$, d.f. $\left.=1, P=0.042\right)$. No other symptom showed a gender difference.

\section{Antecedent stressors}

Antecedent stressors were sought with the question: 'Has the child experienced any of the following life stresses [seven stresses were listed] within a year to the onset of this episode of conversion disorder?' Results are detailed in Table 2. Any type of antecedent stressor was reported in 161/199 (80.9\%) of cases. Out of the possible stressors listed, experience of bullying or victimisation was most common, reported for a quarter. Other comparatively common antecedents were parental separation and death of a relative or friend. There were no differences in frequency of stressors between younger (less than 10 years) and older children (10-15 years) or across gender. Table 2 also gives details of comorbid past and concurrent psychiatric and medical problems.

\section{Personal psychiatric and medical history}

A total of $78 \%(160 / 204)$ of individuals with data on psychiatric history had had no mental disorder prior to the episode of conversion disorder. Of those with a premorbid psychiatric diagnosis, anxiety disorder was reported in 21/200 (11\%) and depressive disorder in 10/194 (5\%). Similarly, more children presented with concurrent anxiety disorders than depressive disorder (Table 2).

\begin{tabular}{|c|c|}
\hline & $n / N(\%)^{a}$ \\
\hline \multicolumn{2}{|l|}{ Antecedent stressors } \\
\hline Bullying requiring school action & $44 / 185(23.8)$ \\
\hline Parental separation & $35 / 184(19.0)$ \\
\hline Death of a relative or friend & $31 / 186(16.7)$ \\
\hline Hospital admission of a parent or sibling & 22/182 (12.1) \\
\hline School examination & 21/180 (11.7) \\
\hline Break up with a best friend & 16/181 (8.8) \\
\hline Abuse requiring social services referral & $12 / 181(6.6)$ \\
\hline \multicolumn{2}{|l|}{ Psychiatric disorder coexisting with conversion disorder } \\
\hline Anxiety disorder & $36 / 198(18.2)$ \\
\hline School phobia & 16/191 (8.4) \\
\hline Depressive disorder & 17/193 (8.8) \\
\hline Conduct disorder & $5 / 189(2.6)$ \\
\hline Post-traumatic stress disorder & $5 / 188(2.7)$ \\
\hline Autism spectrum disorder & 3/188 (1.6) \\
\hline Attention-deficit hyperactivity disorder & $1 / 188(0.5)$ \\
\hline \multicolumn{2}{|c|}{ The six most commonly reported medical problems/symptoms in the year leading up to diagnosis of conversion disorder ${ }^{b}$} \\
\hline Non-epileptic neurological conditions (e.g. cerebral palsy, hydrocephalus) & $11(10.5)$ \\
\hline Abdominal pain & $10(9.5)$ \\
\hline Epilepsy/seizures & $9(8.6)$ \\
\hline Cardiac symptom & $5(4.8)$ \\
\hline Headache & $5(4.8)$ \\
\hline Chest pain & $4(3.8)$ \\
\hline
\end{tabular}


About half $(93 / 192,48 \%)$ of the individuals with data on medical history had required paediatric in-patient and/or outpatient consultation in the 1 year to onset of conversion disorder symptoms. These were reported as still active at the time of diagnosis of conversion disorder in 46/91 (50.5\%). In total, 105 of the 192 individuals with data on medical history had a specific condition or symptom reported. A wide variety of problems were reported and the most common are detailed in Table 2.

\section{Family history of psychiatric and medical conditions}

In total, 26\% (52/201) of individuals with data on family history of mental illness had a family member diagnosed with a psychiatric disorder in the 1 year preceding onset of conversion disorder. The most common conditions were depressive (30/191, $16 \%)$ and anxiety disorders (17/189, 9\%); a family history of conversion disorder was reported in 6/186 (3\%). For 45/195 $(23 \%)$ there was a family member diagnosed with a medical condition in the 1 year to the onset of the child's conversion disorder. The most common diagnoses were neurological conditions (excluding epilepsy), which were reported in 14/184 $(7.6 \%)$, epilepsy noted in $6 / 180(3.3 \%)$ and cancer reported in $6 / 181$ (3.3\%). Non-epileptic seizures were not significantly more common in children with a family history of seizures $(3 / 5,60 \%$ v. 43/99, 43\%, Fishers Exact Test, $P=0.65$ ).

\section{Medical investigations and management}

The case management was resource intensive. In total 161/204 (79\%) individuals with complete data about admission required in-patient admission. For the 125 children who had been discharged at the time of reporting, the median duration of admission was 7 days (range 1-217, IQR 3-14). However, for the 12 individuals who were still in-patients at the time of reporting, the median duration of admission to date was 50 days (range 5-140, IQR 28-111). There was no significant difference between younger (less than 10 years) and older children (10-15 years) in their likelihood of being admitted.

The children had extensive medical investigations (Table 3), most commonly magnetic resonance imaging, electroencephalograms and computed tomography scans. The median number of investigations was 2 (range $0-17$, IQR 1-3). They were supported by a wide range of professionals (Table 3 ). The median number of professionals involved was 4 (range 1-10, IQR 3-5). Psychotropic

\begin{tabular}{|c|c|}
\hline & $n / N(\%)^{a}$ \\
\hline \multicolumn{2}{|l|}{ Investigations } \\
\hline Magnetic resonance imaging & $125 / 188(66.5)$ \\
\hline Electroencephalogram & 95/186 (51.1) \\
\hline Computed tomography scan & $47 / 171(27.5)$ \\
\hline X-ray & 40/171 (23.4) \\
\hline Nerve conduction & $14 / 166(8.4)$ \\
\hline Electromyography & $12 / 165(7.3)$ \\
\hline Video telemetry & $11 / 164(6.7)$ \\
\hline \multicolumn{2}{|l|}{ Professionals } \\
\hline \multicolumn{2}{|l|}{ Medical practitioners } \\
\hline General paediatrician & 175/192 (91.1) \\
\hline Child and adolescent psychiatrist & $129 / 187(69.0)$ \\
\hline Paediatric neurologist & $104 / 170(61.2)$ \\
\hline \multicolumn{2}{|l|}{ Other professionals } \\
\hline Education staff (e.g. teachers) & $110 / 165(66.7)$ \\
\hline Clinical psychologist & 79/164 (48.2) \\
\hline Physiotherapist & $83 / 161(51.6)$ \\
\hline Occupational therapist & $32 / 149(21.5)$ \\
\hline Social worker & 29/147 (19.7) \\
\hline Educational psychologist & $11 / 140(7.9)$ \\
\hline
\end{tabular}

medications, mainly antidepressants, were prescribed for 27/204 $(13.2 \%)$ in the course of the study.

\section{1-year outcome}

Follow-up data were available for 147/204 confirmed cases $(72.1 \%)$, more so for boys than girls $(43 / 51$ (84\%) v. 104/153 $(68 \%), \chi^{2}=5.1$, d.f. $\left.=1, P=0.017\right)$. Individuals for whom there were follow-up data did not differ significantly from those without follow-up data on age, core symptoms, duration of admission or median number of investigations. The median duration of out-patient treatment was 24 days (range 0-156, IQR 8-52). Table 4 shows that most symptoms were reported as improved.

A total of 32/115 (28\%) individuals with completed data were diagnosed with a new psychiatric disorder during the follow-up period. The three most common diagnoses were anxiety disorder $(15 / 105,14 \%)$, depressive disorder $(14 / 105,13 \%)$ and school phobia $(9 / 101,9 \%)$.

Table 4 Outcome of conversion disorder symptoms at 12-month follow-up

\begin{tabular}{|c|c|c|c|c|c|}
\hline \multirow[b]{2}{*}{ Symptom } & \multicolumn{2}{|c|}{$n$} & \multicolumn{3}{|c|}{ Outcome, $n(\%)$} \\
\hline & Reported originally & Known outcome ${ }^{a}$ & Improved & Not improved & Worse \\
\hline \multicolumn{6}{|l|}{ Core conversion symptoms } \\
\hline Non-epileptic seizures & 66 & 38 & $35(92.1)$ & $2(5.3)$ & $1(2.6)$ \\
\hline Motor weakness & 114 & 63 & $58(92.1)$ & $4(6.3)$ & $1(1.6)$ \\
\hline Paralysis & 34 & 29 & $29(100)$ & $0(0)$ & $0(0)$ \\
\hline Abnormal movement & 73 & 31 & $28(90.3)$ & $2(6.5)$ & $1(3.2)$ \\
\hline Hearing loss & 12 & 9 & 7 (77.8) & $1(11.1)$ & $1(11.1)$ \\
\hline Visual loss & 37 & 20 & $16(80.0)$ & $3(15.0)$ & $1(5.0)$ \\
\hline Loss of speech & 30 & 12 & $9(75.0)$ & $2(16.7)$ & $1(8.3)$ \\
\hline Diminished consciousness & 47 & 18 & $17(94.4)$ & $1(5.6)$ & $0(0)$ \\
\hline Anaesthesia/paraesthesia & 56 & 20 & $18(90.0)$ & $2(10.0)$ & $0(0)$ \\
\hline \multicolumn{6}{|l|}{ Associated non-core symptoms } \\
\hline Pain & 96 & 42 & $37(88.1)$ & $5(11.9)$ & $0(0)$ \\
\hline Fatigue & 55 & 27 & $22(81.5)$ & $4(14.8)$ & $1(3.7)$ \\
\hline La belle indifference & 45 & 30 & $21(70.0)$ & $9(30.4)$ & $0(0)$ \\
\hline
\end{tabular}


Clinicians offered the children's families a non-medical explanation for the conversion disorder symptoms in the vast majority of cases $(116 / 124,94 \%)$. For the children with complete data for this analysis most families accepted the non-medical explanation either fully 69/120 (58\%) or partially 39 (33\%): thus over $90 \%$ of families had some level of acceptance for a nonorganic explanation.

The psychological interventions offered and accepted by families were: psychoeducation $(49 / 89,55 \%)$, supportive counselling $(41 / 80,51 \%)$, anxiety management such as relaxation training (34/ $69,49 \%)$, family therapy $(26 / 68,38 \%)$ and cognitive-behavioural therapy $(15 / 53,28 \%)$.

\section{Discussion}

This is the first study to prospectively investigate the incidence of conversion disorder in children in a European population. With 204 cases, this is the largest cohort of incident cases of nontransient childhood conversion disorder reported in the medical literature. The incidence was low but increased with age. The cases were often complex as comorbid medical symptoms and psychiatric disorders were commonly reported. Most conversion symptoms improved over the 12 months of follow-up but there was high use of health and other professional services.

\section{Incidence}

The total yearly incidence of $1.30 / 100000$ (95\% CI 1.11-1.52) is about half that reported from Australia $(2.3-4.2 / 100000)$ in a study that used a similar methodology. ${ }^{2}$ This may be explained by our study using a case definition that excluded transient (under 7 days) symptom duration unlike the previous study that did not specify duration. Another possible explanation is underreporting of cases: whereas the BPSU reporting system is well established with return rates of $93 \%$, the CAPSS system is still in an early phase of development and the card return rate during the study was $66 \%$. This compares with an overall $96 \%$ return rate in the Australian study. Data for 129 reports were not returned in our study. Given that the rate of verified case reports was 61\% (204/ 337), this extrapolates to a potential 79 additional cases, which would raise the incidence to $1.8 / 100000$.

Our study indicates that conversion disorder is less common in children than in adults where incidence rates of 5-12 per 100000 have been reported. ${ }^{7}$ The higher incidence in adults could be related to the role of trauma in the pathogenesis of conversation disorder, ${ }^{8}$ such that the cumulative effect of trauma in the journey from childhood to adulthood would increase the risk. It might also be related to developmental immaturity, since we, as in previous studies, ${ }^{2}$ found the incidence to be lower in the younger children.

\section{Demographics}

The median age of the children in our study (12.5 years) is similar to the Australian survey's (11.8 years). ${ }^{2}$ Both studies showed a preponderance of females (over 70\%), and in ours this was as marked in the younger as in the older age group. This may be linked to the high representation of non-epileptic seizures in our study, a symptom where female gender is especially overrepresented. ${ }^{9}$

Consistent with other studies, ${ }^{2,3,10}$ we found the incidence of conversion disorder to increase with age: in fact no children reported were below the age of 7 . This has been attributed to immaturity in young children in the development of the social skills and ability to see themselves from another person's perspective, ${ }^{11}$ which is necessary for the display of the range of interpersonal behaviours that are an integral part of somatising syndromes in children. ${ }^{12,13}$

\section{Clinical presentation}

Children presented with a wide range of clinical features: as in previous reports, ${ }^{2,4}$ motor symptoms and non-epileptic seizures were most commonly reported and multisymptomatic presentations common. Antecedent stressful events were reported for $80.8 \%$ of individuals. This again is comparable to the results of the Australian surveillance study and confirms the perceived significance of stress.

The main stresses in our sample were related to bullying requiring school action, although examinations and break up with friends were also mentioned, as were parental separation, illness and losses. The findings are generally in line with previous reports. ${ }^{2,4}$ Taken together these findings highlight the importance of stressors involving school and relationships, rather than major breakdowns in family relationships and boundaries such as in child abuse as reported in the adult literature. ${ }^{8,14}$ This may be accounted for by retrospective overreporting of child abuse by adult patients or underreporting in childhood studies like ours. The exact nature and causal importance of the reported antecedent stressors is not determinable by our study.

Past or current psychiatric comorbidity (usually anxiety and depressive disorders) was reported for about a quarter of individuals, in line with previous reports from both clinical surveillance and psychiatric clinical samples. ${ }^{4}$ Management frequently involved paediatric in-patient admission, performance of special investigations and contact with a large number of health and educational professionals, and we identified a small number of children with prolonged hospital admissions as part of the assessment procedure. This reflects the diagnostic difficulties and concerns about the possibility of organic illness before a final diagnosis is reached, and illustrates the cost of these problems and the requirement for paediatric and psychiatric expertise.

\section{1-year outcome}

The follow-up findings confirm previous reports of improvement over time for many children. ${ }^{4}$ Nevertheless, some symptoms persisted, and a quarter of the children developed a new psychiatric disorder during follow-up, especially anxiety and depressive disorders, possibly representing progress away from somatic to emotional expression of distress in some children.

The rate of improvement in core conversion disorder symptoms in our study (75-100\%) is higher than that reported for adult patients. For example, Crimlisk and colleagues ${ }^{15}$ reported resolution or improvement in $58 \%$ of individuals in a 6-year follow-up of adult patients from a national centre. Adult patients in that study would have had more severe index episodes; hence their referral to a specialist neurology hospital. However, our follow-up period was shorter and it is possible that individuals with no follow-up data showed less improvement, leading to overestimation of overall positive outcomes.

The follow-up data indicate that most families displayed some degree of acceptance of the non-medical explanation for the symptoms, and about a half received psychological treatments, confirming the feasibility of helping many families move from a medical to a mental health perspective and of putting into place psychosocial interventions. ${ }^{16}$ Nevertheless, a small percentage failed to accept a non-medical framework for understanding the problems, and therefore are likely to remain a challenge for clinicians.

As a result of the relatively short duration of follow-up, we do not know whether the reported improvements were maintained or whether a proportion of the children subsequently developed other psychosocial difficulties. Data from follow-up of adult patients attending specialist centres suggest increased levels of psychiatric diagnoses long term. ${ }^{15}$ 


\section{Strengths and limitations}

The main strengths are the high ascertainment of cases from a complete national population. This was made possible by the dual surveillance strategy that enabled reports by paediatricians and child and adolescent psychiatrists.

The first limitation is that surveillance methodology only identifies individuals whose cases are severe enough to present to secondary care and to the attention of consultant paediatricians and child and adolescent psychiatrists. This is underscored by our focus on non-transient cases. Moreover, we might have missed children seen by adult neurology, ophthalmology or psychiatric services who side-stepped paediatric services, although this seems unlikely given service organisation in the UK and Ireland. Second, we were unable to confirm the eligibility of a quarter of reported cases due to clinicians not returning the initial questionnaires despite several reminders, and the lower card-return rate for CAPSS was also a limitation, suggesting that our incidence may be an underestimate. Third, and as already stated, follow-up data on individual symptom change were only available for a proportion of cases and this finding should therefore be regarded with caution. Finally, although most families for which this information was available showed some level of acceptance of a non-medical explanation, we had no data on the children's own understanding or acceptance of this formulation

\section{Clinical implications}

Although uncommon, conversion disorder presents a diagnostic challenge to clinicians and consumes considerable diagnostic and clinical resources. Rare conditions such as non-transient conversion disorder lack coherent national plans for assessment and treatment. Its rarity, complexity and the commonly reported associated psychiatric and psychosocial factors point to the importance of the availability of specialist services with expertise in both biological and psychiatric aspects. These services may be in the best position to provide the breadth of experience and expertise necessary to confidently manage the disorder or to advise other clinicians.

Uncommon disorders often lack the robust evidence base to guide treatment as the numbers required for randomised trials are often too difficult to obtain. This study provides epidemiological evidence about incidence, duration and severity in order to inform the development of possible future intervention studies.

\section{Funding}

The project was funded by the BUPA Foundation

\section{Acknowledgements}

We would like to thank Vasanthi James for running the administration of the study, and Nicole Hickey for additional administrative support. We thank the executive committees of BPSU and CAPSS for facilitating the study. We thank the thousands of consultant paediatricians and child and adolescent psychiatrists who returned the study notification cards. Finally, we thank BUPA foundation for funding the project. We acknowledge the BPSU, supported by the Department of Health, for facilitating the data collection and the reporting clinicians, particularly those who completed the questionnaires.

Cornelius Ani, MBBS, DCH, MSC, MRCP, MRCPsych, MD(Res), Academic Unit of Child and Adolescent Psychiatry, Imperial College London and Berkshire Healthcare NHS Foundation Trust, Bracknell Child and Adolescent Mental Health Services, Bracknell; Richard Reading, FRCPCH, MD, Jenny Lind Department, Norfolk and Norwich Richard Reading, FRCPCH, MD, Jenny Lind Department, Norfolk and Norwich
University Hospital, Norwich; Richard Lynn, BSc, MBPSS, MSc, British Paediatric Surveillance Unit, Royal College of Paediatrics and Child Health, London; Simone Forlee, MBChB, DCH, MRCPCH, MRCPsych, Oxford City Child and Adolescent Mental Health Services, Oxford; Elena Garralda, MD, FRCPsych, FRCPCH, MPhil, DPM, Academic Unit of Child and Adolescent Psychiatry, Imperial College London, UK

Correspondence: Cornelius Ani, Academic Unit of Child and Adolescent Psychiatry, Imperial College London, St Mary's Campus, Norfolk Place, London W2 1PG, UK. Email: c.ani@imperial.ac.uk

First received 21 Jun 2012, final revision 16 Jan 2013, accepted 6 Feb 2013

\section{References}

1 American Psychiatric Association. Diagnostic and Statistical Manual of Mental Disorders (4th edn) (DSM-IV). APA, 1994.

2 Kozlowska K, Nunn K, Rose D, Morris A, Ouvrier R, Varghese J. Conversion disorder in Australian paediatric practice. J Am Acad Child Adolesc Psychiatry 2007; 46: 168-75.

3 Grattan-Smith P, Fairley M, Procopis P. Clinical features of conversion disorder. Arch Dis Child 1988; 63: 408-14.

4 Pehlivanturk B, Unal F. Conversion disorder in children and adolescents: a 4-year follow up study. J Psychosom Res 2002; 52: 187-91.

5 Verity C, Preece M. Surveillance of rare disorders by the BPSU. Arch Dis Child 2002; 87: 269-71.

6 Lynn R, Viner R, Nicholls D. Ascertainment of early onset eating disorders: a pilot for developing a national child psychiatric surveillance system. Child Adolesc Ment Health 2012; 17: 109-12.

7 Akagi $\mathrm{H}$, House A. The clinical epidemiology of hysteria: vanishingly rare, or just vanishing? Psychol Med 2002; 32: 191-4.

8 Roelofs K, Keijsers G, Hoogduin K, Naring G, Moene F. Childhood abuse in patients with conversion disorder. Am J Psychiatry 2002; 159: 1908-13.

9 Bass C. Conversion and dissociation disorders. In New Oxford Textbook of Psychiatry (eds M Gelder, N Andreasen, J Lopez-lbor, J Geddes): 1011-20. Oxford University Press, 2009.

10 Kotagal $P$, Costa M, Wyllie E, Wolgamuth B. Paroxysmal nonepileptic events in children and adolescents. Pediatrics 2002; 110: e46.

11 Hetherington EM, Parke RD. Child Psychology: A Contemporary Viewpoint (5th edn). McGraw Hill, 2003.

12 Taylor DC. Hysteria, play-acting and courage. Br J Psychiatry 1986; 149: 37-41.

13 Garralda E. Unexplained physical complaints. Pediatr Clin N Am 2011; 58: 803-13.

14 Sar V, Akyüz G, Kundakçi T, Kiziltan E, Dogan O. Childhood trauma, dissociation, and psychiatric comorbidity in patients with conversion disorder. Am J Psychiatry 2004; 161: 2271-6.

15 Crimlisk H, Bhatia K, Cope H, David A, Marsden C, Ron M. Slater revisited: 6 year follow up study of patients with medically unexplained motor symptoms. BMJ 1998; 316: 582-6.

16 Leslie SA. Diagnosis and treatment of hysterical conversion reactions. Arch Dis Child 1988; 63: 506-11. 